\title{
Learning Objects as Tools for Teaching Information Literacy Online: A Survey of Librarian Usage
}

\section{Lori S. Mestre, Lisa Baures, Mona Niedbala, Corinne Bishop, Sarah Cantrell, Alice Perez, and Kate Silfen}

\begin{abstract}
Based on information gathered from two discussion sessions moderated by members of the Education and Behavioral Sciences Section's Online Learning Research Committee a survey was conducted to identify how librarians use course/learning management systems and learning objects to deliver instruction. Objectives of the study were to identify the experiences of librarians who are using course/learning management systems; in what context learning objects are being developed and used; and the pedagogical considerations by librarians when creating online learning materials. In addition to discussing the results of the survey, a description of a "Toolkit for Online Learning" created by the Online Learning Research Committee is provided.
\end{abstract}

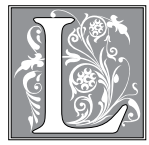

ibrarians are now engaged in providing library and information literacy instruction through many venues. Whether as instructors of a one-shot instruction session for face-to-face or online students, as online course instructors, or as embedded librarians in online courses that use a course/learning management system, knowledge of pedagogical theories and instructional design of learning objects/modules is vital. The importance of acquiring a sound knowledge base in pedagogical theories is readily appar- ent as highlighted in the Association of College and Research Libraries (ACRL) book entitled Practical Pedagogy for Library Instructors: 17 Innovative Strategies to Improve Student Learning edited by Douglas Cook (a member of EBSS) and Ryan L. Sittler. ${ }^{1}$ This publication, a collection of case studies exploring teaching theories and practices, aptly illustrates the need to incorporate instructional design principles into the development and delivery of information literacy instruction.

Members of the Online Learning Research Committee of the ACRL Education

\footnotetext{
Lori Mestre is Head of the Undergraduate Library at the University of Illinois at Urbana-Champign, e-mail: Imestre@illinois.edu; Lisa Baures is Public Services Librarian/College of Education Liaison at Memorial Library, Minnesota State University, e-mail: lisa.baures@mnsu.edu; Mona Niedbala is Education E Curriculum Materials Librarian at University of Rhode Island, e-mail: mflorea@mail.uri.edu; Corinne Bishop is Information Literacy Librarian at University of Central Florida, e-mail: Corinne.Bishop@ucf.edu; Sarah Cantrell is Education Services Librarian at Dahlgren Memorial Library, Georgetown University, e-mail: sec62@georgetown.edu; Alice Perez is Librarian for Psychology, Cognitive Science E Education at the Social Sciences E Humanities Library, University of California-San Diego, e-mail: ajperez@ucsd.edu; and Kate Silfen is Reference Librarian at Boston College, e-mail: silfen@bc.edu.
} 
and Behavioral Sciences Section (EBSS) began to develop a toolkit to address the need for information about online instruction pedagogy and Web 2.0 tools. The committee quickly realized that the voices of librarians and their experiences, practices, and knowledge would be crucial to the completion of the toolkit. The quest for such information led the committee to moderate two discussion groups. The first session, "Facilitating Discussions as an Online Instructor", was held at the American Library Association (ALA) 2009 Midwinter Conference. The second session "Training to Be an Online Instructor" was held at the ACRL biennial conference (2009). High attendance at the discussion sessions demonstrated an interest on the part of librarians to acquire the requisite skills for creating, using, and reusing online learning objects to deliver information literacy instruction. Topics such as selecting the most efficient online course/learning management system or the best Web 2.0 software for online, hybrid, or webenhanced library instruction animated the conversations. Additional themes that emerged from the discussions included the importance of collaborating with faculty in the design of learning objects and identifying tools and practices for active learning and student engagement.

Information compiled from the two discussion groups was used to create a survey from which the results would present an environmental scan of online learning and the use of learning objects and software applications within the library community. Objectives of the study were to identify how librarians interact with students and faculty online; the types of discussion and communication strategies used; and in what context learning objects are developed and used. Examples of how librarians are interweaving social networking and open access tools into online instruction were also compiled. This article presents the survey results and a description of the "Toolkit for Online Learning" developed by the Online Learning Research Committee.

\section{Literature Review}

Librarians are not only partners and guest lecturers in online library and information literacy instruction, but they may also serve as the sole instructors. Consequently, it is important for them to have the necessary tools and knowledge to help them succeed when using this platform. Design principles for online instruction should not consist of the mere transfer of face-to-face instruction to the online environment. Effective online instruction is based on sound educational psychology and pedagogical principles. Implementing strategies for engaging students, moderating dialogs, creating and evaluating assignments based on student learning outcomes, and motivating students to learn through the effective use of technology ensures the incorporation of "best practices." The following section provides a context for the intersection of information literacy, pedagogic theory, and instructional design as librarians explore their expanding role in online learning environments and in the development of online learning objects.

\section{Learning Objects: Definitions and Purpose}

Definition of learning objects. Broadly defined, a learning object is a reusable instructional resource, usually digital and Web-based, developed to support learning. Librarians create and use many types of learning objects to deliver instruction. There is no single standard for designing and/or developing learning objects. Available in a number of formats, learning objects can encompass text-based learning modules and lessons as well as animated and streamed video presentations. Wiley ${ }^{2}$ outlines the basic concept of learning objects as "small (relative to the size of an entire course) instructional components that can be reused a number of times in different learning contexts." ${ }^{\prime 3}$ Some common examples of learning objects are instructional modules, tutorials, instructional games, blogs, research guides, narrated PowerPoint presenta- 
tions, podcasts, photos, images, quizzes, surveys, tutorials, and videos.

Core characteristics of learning objects include efficiency (for instance, cost and time saving), ${ }^{4}$ reusability, interoperability, durability, and accessibility. ${ }^{5}$ Additional characteristics to consider include facilitation of competency-based learning, increased value of content, and customization. ${ }^{6}$ Learning objects could be course-based but also remedial, allowing for a "just-in-case, just-in-time, just-foryou" approach. $^{7}$

Viewing learning objects from the perspective of how they are accessed provides a similar yet slightly different conceptualization. Jackson and Mogg describe an Information Literacy Resource Bank at Cardiff University in the United Kingdom as a collection containing "bite-size" interactive tasks, images, diagrams, cartoons, and short tutorials for use by both librarians and faculty as a means of promoting the embedment of information literacy into the curriculum. ${ }^{8}$ Both of the mentioned perspectives or conceptualizations of learning objects provide instructional value.

Purpose of learning objects. Librarians already use a variety of learning objects in their face-to-face and online instruction. The literature emphasizes the use of learning objects to enhance and enrich students' learning experiences. ${ }^{9}$ Like LEGOs, learning objects, which often consist of "small definable chunks of learning," can be used as building blocks to build concepts that address specific learning objectives or to create multiple learning experiences. ${ }^{10}$ Providing an engaging environment for students "to learn in as opposed to one to learn from" reflects the underlying principles associated with the design and implementation of learning objects. ${ }^{11}$

Mardis and Ury describe the use of learning objects for library instruction as a means to introduce content, gauge prior knowledge, reinforce understanding, assess learning, save development time, and personalize curriculum. ${ }^{12}$ Reus- able learning objects can be used both in synchronous and asynchronous courses, as well as in reference environments to scaffold student learning. The Mardis and Ury survey results indicated that students who recommend the use of learning objects in courses preferred those that incorporated both video and text, were visually engaging, and were available at point of need. In the results of the EBSS Online Learning Research Committee survey, librarians expressed an interest in learning how to create just this type of online instruction.

\section{Models of Instructional Design}

Whether used as a standalone resource, embedded within a course, or integrated into course curriculum, creating pedagogically sound learning objects is essential if the instruction is to be effective. One theoretical model applicable to the development of learning objects is that of Dick, Carey, and Carey. ${ }^{13}$ This model reflects a systematic approach to instructional design based on nine components: identification of instructional goal(s); instructional analysis; analysis of learners and context; articulation of performance objectives; development of assessment instruments; development of instructional strategies; development and selection of instructional materials; design and implementation of formative evaluation of instruction; and the revision of instruction based on evaluation results. This model provides step-by-step guidance for creating instruction modules and is easily adaptable to the design and development of learning objects. In addition to identifying goals and objectives for the creation of the learning object, these same objectives can be stated within the object itself so that the user is clear as to the purpose and expected outcomes of the experience. The analysis of both learners and the object is also important. The developer needs to consider which format is the most appropriate, along with addressing multiple learning styles. To inform needed adjustments in the instructional materials, 
usability testing should be conducted and feedback from learners solicited. Within the learning object, checkpoints (formative assessments) can be interspersed to aid in, as well as to measure, student comprehension, and to assist in measuring the effectiveness of the method of the delivery and also the instruction.

Another model to consider when creating learning objects is "Understanding by Design" developed by Wiggins and McTighe. ${ }^{14}$ Based on the backward design of instruction method, this model proposes "an approach to designing a unit that begins with the end in mind and designs toward the end." 15 Consisting of three stages-desired results, accepted evidence of learning, and planning instruction and learning experiences - the goal of the model is to build deep, long-term understanding to help students to connect facts and to transfer acquired knowledge and skills to new contexts. A "student understands when he/she can explain, interpret, apply, have perspective, empathize, and demonstrate self-knowledge."16 This model has particular relevancy to the development of learning objects because of the strong emphasis that is placed on knowledge transfer and critical thinking skills. This model negates the development of passive learning objects where the student simply watches or listens while the instruction is being delivered. Conversely, "Understanding by Design" requires students to be actively engaged with the material being presented by prompting them to apply the information or to work with the information in some new way. Consequently, this model challenges instructors to address the following questions as they develop learning objects: Does the learning object allow for active learning and critical thinking activities? Does the student need to apply the knowledge immediately? In fact, these are some of the very questions respondents in the present survey asked when offered the opportunity to provide further comments.

Thompson and Yonekura of the University of Central Florida present a some- what more simplified model that includes the following components: statement of a learning objective; presentation of content; an opportunity for practice; and assessment based on the achievement of the objective. ${ }^{17}$ According to this model, all four elements must be present for a component to be considered a learning object.

The above pedagogic models relate especially well to the design and development of learning objects, such as tutorials that librarians create using screencasting tools (such as Camtasia, Captivate, or Flash). However, wikis, blogs, and threaded discussions can also be considered learning objects. These tools could be used when working with a community of learners. One theory that is related to the construction of these types of tools is the Knowledge Building theory. This theory is "the production and continual improvement of ideas of value to a community, through means that increase the likelihood that what the community accomplishes will be greater than the sum of individual contributions and part of a broader cultural effort." 18 This theory is based on the notion of collective cognitive responsibility; knowledge building implies that each and every member is responsible for contributing to the success of a group effort. ${ }^{19}$ Though it is often associated with group or peer work, knowledge building can also be applied to learning objects that provide opportunities for students to submit editorial comments using tools such as wikis, blogs, or threaded discussions. In these instances, the instructor or librarian will need to understand how to effectively set up the tool to engender a sense of community among students to encourage participation in answering questions, to critically examine various scenarios, and to provide feedback. In the discussions and survey conducted by the EBSS Online Learning Research Committee, respondents indicated a need to learn how to work with tools to effectively engage learners and promote learning. 
Various researchers and authors have debated whether constructivist learning theory adds to or detracts from e-learning pedagogy, given that knowledge construction is based on previous individual experience that may or may not mitigate the benefits to be derived from student-to-student interaction. ${ }^{20}$ Regardless, in the design of learning activities embedded within learning objects, it is important to ask whether the activity: (1) focuses on addressing diverse perspectives; (2) requires higher-order thinking skills; (3) represents real-world examples; (4) provides scaffolding to assist students to move beyond what is known; (5) affords opportunities for self-reflection; (6) presents multiple representations of ideas; (7) allows for social negotiation; and (8) assesses the achievement of learning outcomes. These are questions that librarians and educators need to consider as they design and redesign their learning objects.

The development of learning objects incorporating Web 2.0 tools greatly enhances the ability of librarians to interactively engage students in learning activities designed to introduce, provide practice in, and eventually demonstrate mastery of information literacy skills. Because learning objects are reusable, granular, and contextually adaptable, they can be conveniently packaged and readily retrievable from any number of instruction delivery platforms or access points and thereby greatly extend the reach of library instruction.

\section{Methodology}

As previously stated, drawing upon information gathered from facilitated discussions held at two different library conferences and informal conversations with librarians, the committee created a survey based on the following hypotheses.

\section{Hypotheses:}

- Librarians who create online learning objects typically do so without much support or organized training, which may limit the types of objects they can create.

- Librarians who work with faculty who use course management systems usually do so through a faculty course, rather than a library course where students are automatically enrolled. (Note: This is different from a library-created course where students can have guest access.) This may severely limit the access of students to library content unless librarians themselves are able to embed the content within faculty courses.

- When designing learning objects, librarians are generally not aware of best practices or how to design pedagogically sound objects.

\section{Survey}

To assess the accuracy of these hypotheses, the Survey for Learning Object Integration, created by the Online Learning Research Committee of EBSS, was distributed electronically in November 2008. The survey was developed to collect information on librarian participation in online instruction; their integration of library instruction into course management systems; and their use of software and Web technologies to create learning objects and other online instruction materials. To prevent duplication of effort, the survey was reviewed by ACRL and subsequently approved for distribution based on compliance with the Association's established policies, procedures, and guidelines for research and investigative rigor.

An electronic survey was chosen due to the ease with which it could be distributed, the potential for rapid responses, and access to a large sample population. Consisting of 18 questions -5 openended, 12 multiple choice with an "other" option to be filled in by respondents, and 1 true/false - the survey was designed to identify trends in the use of multimedia and Web applications by librarians to deliver online instruction. It is important to note that the survey also focused on documenting patterns of technology use and training. Despite the fact that there was a 


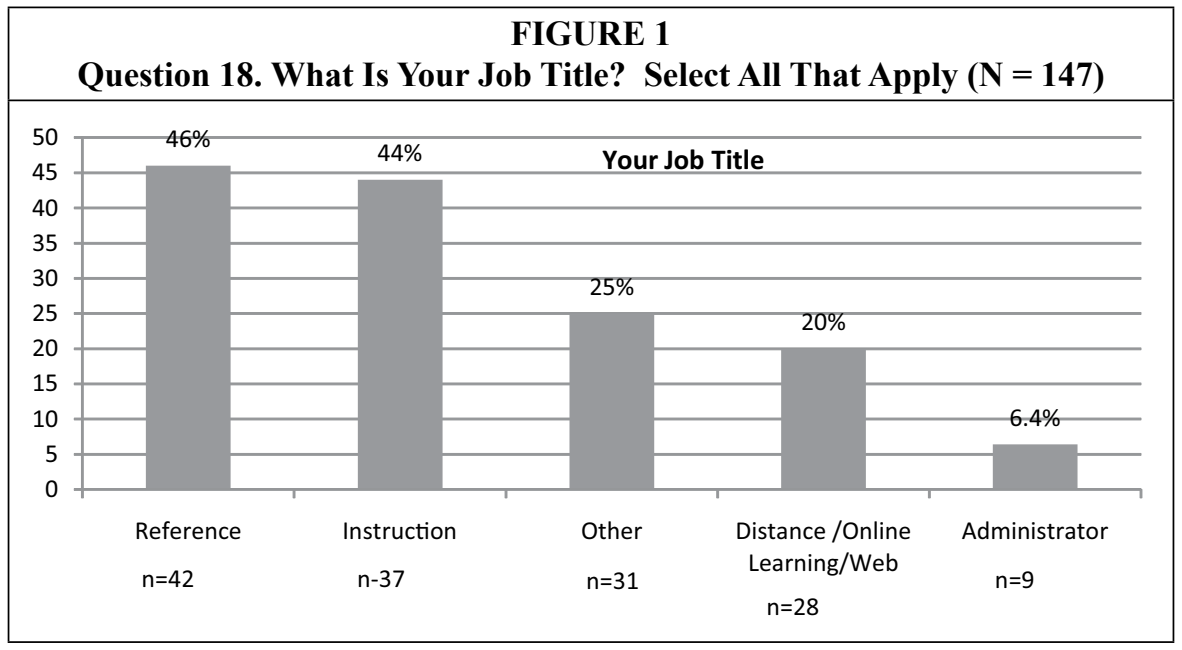

potential to reach thousands of librarians since the survey was distributed to several librarian lists related to information literacy or information technology, the intent was to seek out respondents who both used course management systems and learning objects. Therefore, the number of potential respondents was anticipated to be small; this was indeed the case, with a total of 97 surveys returned.

\section{Characteristics of Survey Respondents}

The vast majority of survey respondents (87 out of 97 ) were librarians from aca- demic institutions, with the remaining 10 respondents representing librarians from school, special, state, consortium, and government libraries.

Job Title. Reference and instruction librarians accounted for 90 percent of the survey respondents. Because respondents could select more than one choice, many indicated that they held positions with responsibilities in multiple areas; therefore, more than one job title was attached to the names of those respondents. Additionally, a few university librarians, department heads, directors of centers, or library directors responded to the survey.

FIGURE 2

Question 1: Which Course Management Systems (Learning Management System) Does Your Institution Use? Select All That Apply $(\mathbf{N}=119)$

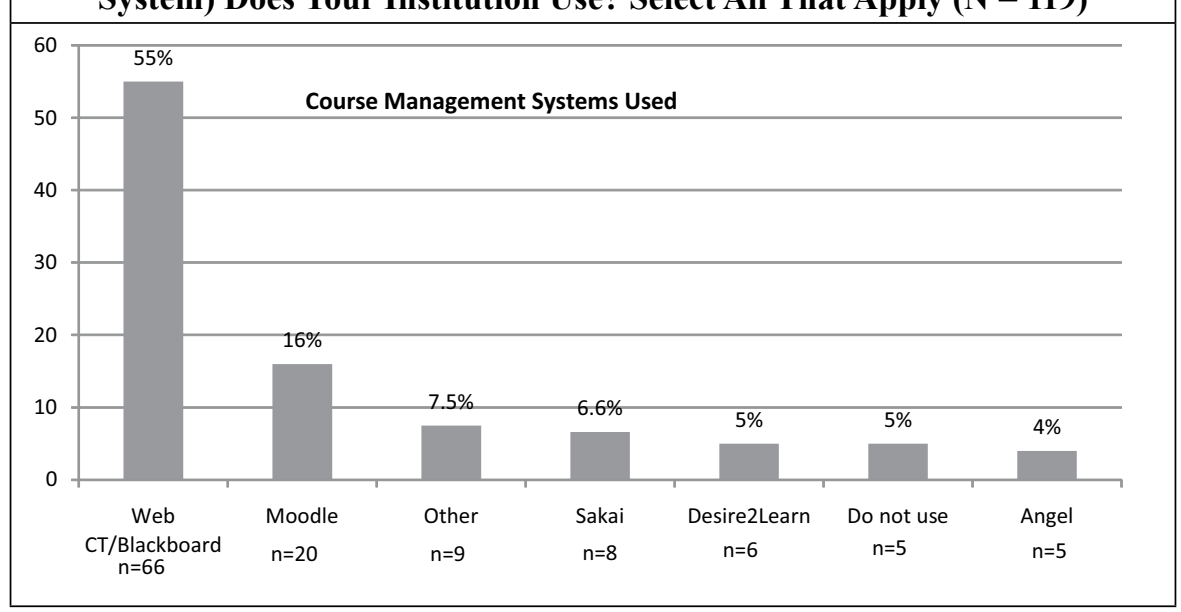




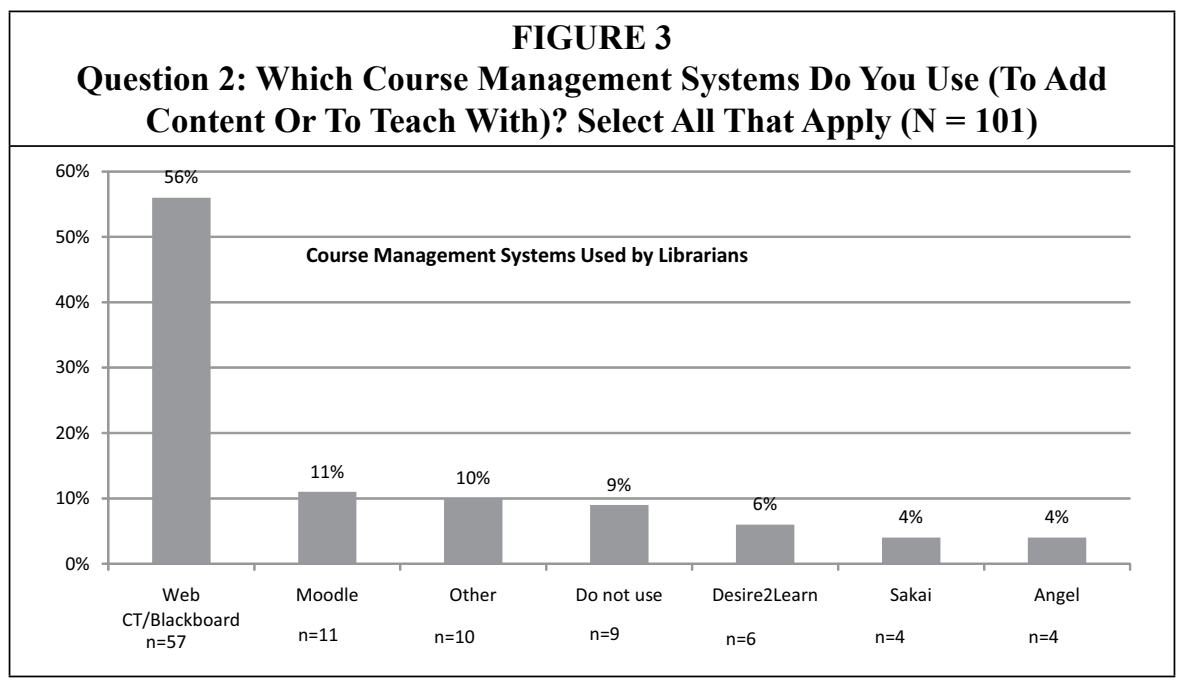

\section{Results}

\section{Course/Learning Management Software Systems Used}

The purpose of the first six survey questions was to discover the various course/ learning management systems used by librarians. Among the top five identified were Angel, Desire2Learn, Moodle, Sakai, and WebCT/Blackboard. The figure above provides the breakdown of responses.

Not surprisingly, course/learning management systems in use by survey respondents reflected those in use on their campuses. Figure 2 provides a breakdown by type of course/learning management systems being used.
Of special note is the use of other types of software applications to perform functions similar to those associated with course/learning management systems. Examples include DimDim, eCollege, LibGuides, Jenzabar, and AdobeConnect, Wetpaint or other wikis.

\section{Administrator and Access Rights for Course Management Systems}

Although survey results indicated respondents often use course management systems, rarely do libraries have their own course/learning management space. Of the libraries represented in the survey using course management systems, only

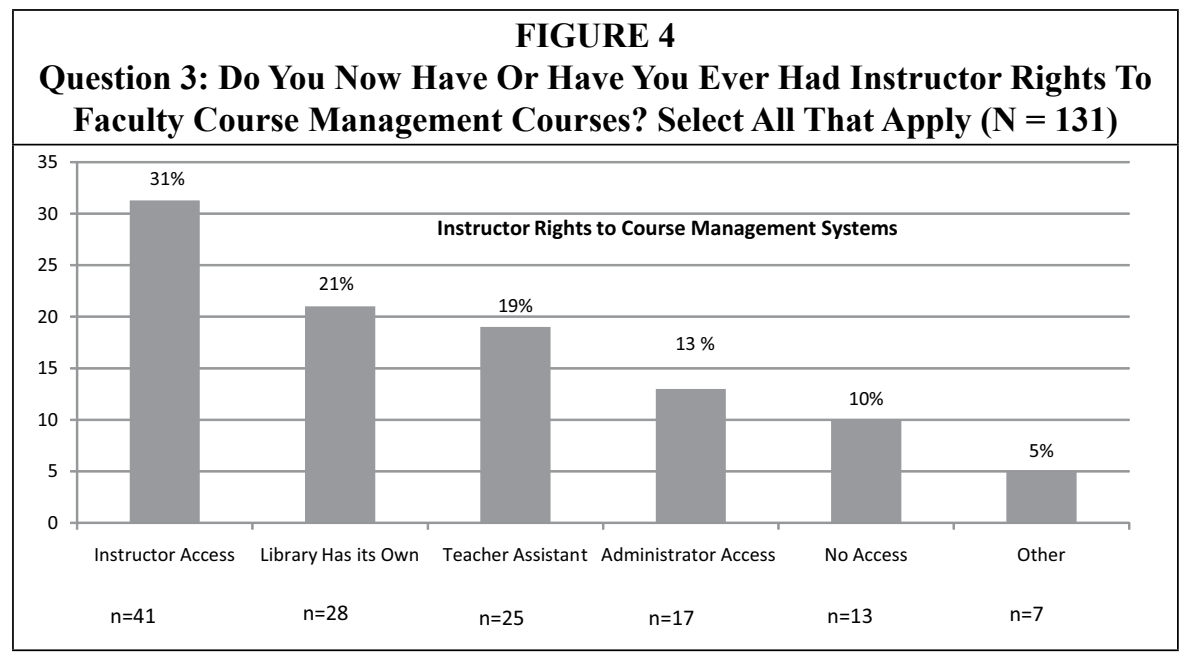




\begin{tabular}{|c|c|c|}
\hline \multicolumn{3}{|c|}{$\begin{array}{c}\text { TABLE } 1 \\
\text { Question 4: Does Your Library } \\
\text { Have its Own Public Course } \\
\text { Management Space (e.g. A Library } \\
\text { Presence that is Accessible to all } \\
\text { Students, not Just those Enrolled in } \\
\text { a Course?) }\end{array}$} \\
\hline & Yes & No \\
\hline Percent & $27 \%$ & $73 \%$ \\
\hline Number $=86$ & 23 & 63 \\
\hline
\end{tabular}

18 percent indicated having administrator rights to course sites. Overall, 92 percent of respondents (including the $18 \%$ with administrator rights) have some form of access to course sites, whether it is as an instructor or as a teaching assistant.

The greatest percentage of survey respondents (44\%) indicated they had been added as an instructor and/or administrator to course sites by faculty teaching the courses. Only seven $(10 \%)$ of the respondents reported having no access to course sites. Even though these seven respondents may not have direct access to course sites, they do send library materials to instructors to be added to course sites. It is clear that most survey respondents, regardless of the level of access to course sites, perceive course/learning management systems as an important venue for promoting library resources and services.

One of the advantages of specifically designating a library space within a course management system is the ability to extend access to all students and develop instruction promoting the acquisition of research skills using library resources and services.

Although $55 \%$ of the respondents indicated they had access to a course management system, the percentages drop dramatically when asked if their library has its own course management space. Only twenty-seven percent of all respondents indicated that their library had space on a course management system, as indicated in Table 1. Of those twenty-seven percent with a designated space in course management systems, thirty-four percent automatically enrolled all students in a library course, with several others offering a library course as an elective. In some cases, the library course sites are open to the public. One respondent indicated that within the institution's course management system their library's support page automatically appears in all course sites.

Sixty-three libraries (73\%) indicated they do not have a designated space on a course/

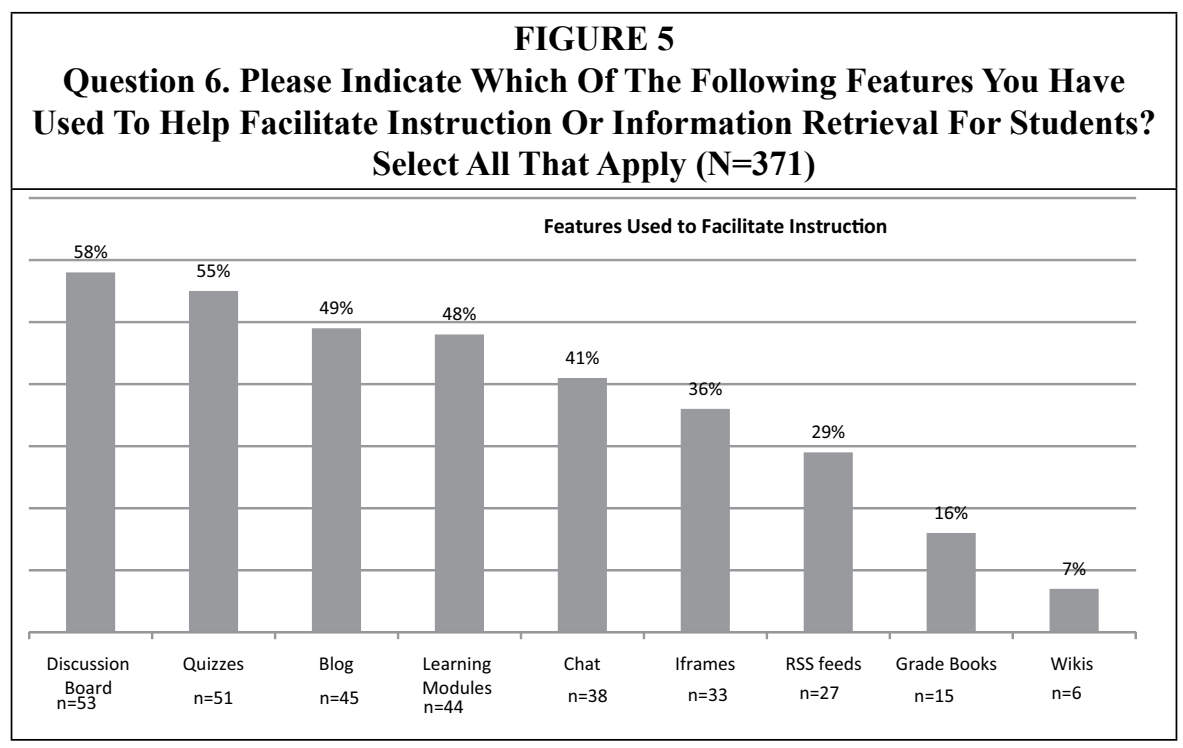


learning management system. These libraries elected to pursue alternative means for providing students with access to library resources and services within course/learning management systems.

\section{Course Management Features Used}

A variety of course/learning management features that may facilitate the acquisition of library research skills are being implemented as illustrated in figure 5 . The most common are the discussion board and quiz tools with 58 percent and 55 percent of survey respondents respectively. Embedding learning modules is another feature of course management systems that survey respondents are using (48\%).

Other tools that respondents used (as indicated in the open response option) included screen cast tools (Wink, Camstudio, Jing), clickers, LibGuides, reference online assistance (Ask a Librarian), Eluminate, Wimba, Articulate, web conferences, video conferences, and Twitter.

\section{Learning Objects Used}

Questions 7 through 12 explored which learning objects librarians are creating and/or adding to course/learning management systems. Survey responses to these questions highlight the wide as- sortment of course management tools and software applications librarians are using to create learning objects and shed light on how librarians are connecting with students in the online environment.

Responses to question 7 indicated that the most common type of learning object created by librarians was tutorials $(35 \%)$. Other responses included videos $(11 \%)$, quizzes $(9 \%)$, research guides $(9 \%)$, PowerPoint presentations $(8 \%)$, surveys $(7 \%)$, blogs $(6 \%)$, podcasts $(4 \%)$, screencasts $(4 \%)$, and wikis $(2 \%)$. The additional 5 percent of responses were for resources not duplicated by other respondents.

In question 8, participants were asked to identify how they familiarize themselves with new technologies or software applications. Because there are many ways to learn new technologies, respondents had the option to check more than one response. The most frequently cited method of learning about new technologies and software applications was to acquire the software and figure it out themselves (68\%). However, some respondents indicated that they also took advantage of workshops and training sessions, most often outside the library, and often on their own time. Figure 6 provides a detailed account of the responses.

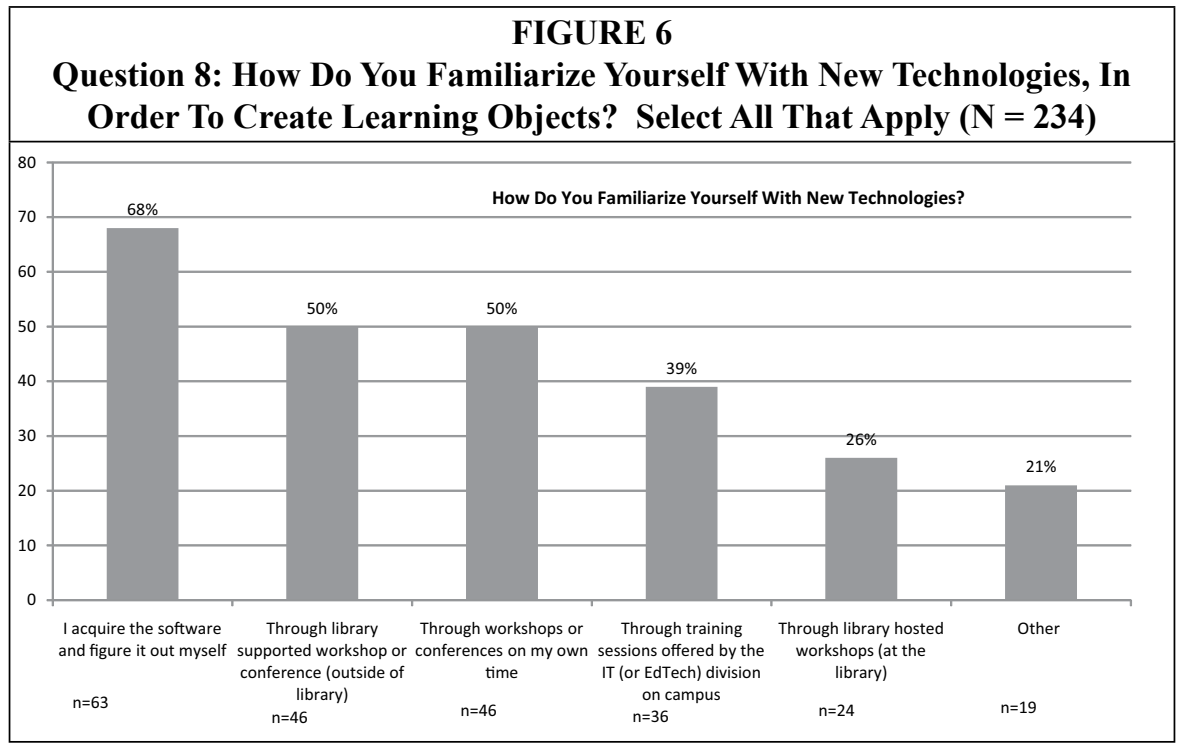




\begin{tabular}{|l|c|c|}
\hline \multicolumn{3}{|c|}{ TABLE 2} \\
$\begin{array}{c}\text { Question 11: Please List the Open } \\
\text { Source Tools You Use. Select All } \\
\text { That Apply (N = 70) }\end{array}$ \\
\hline Tool & Number & Percent \\
\hline Jing & 19 & 27 \\
\hline Audacity & 11 & 16 \\
\hline Wink & 5 & 7 \\
\hline Camstudio & 4 & 6 \\
\hline Gimp & 4 & 7 \\
\hline Moodle & 3 & 4 \\
\hline Hot Potatoes & 3 & 4 \\
\hline
\end{tabular}

Question 9, an open-ended question, identified additional means of learning about new technologies. Responses included reading books, journals, and technology/education blogs; learning informally from colleagues, friends, or instructional designers; learning from faculty or by working with graduate students; using repositories like MERLOT and Animated Tutorials Sharing Project (ANTS); reading listservs and Web-based guides; and researching on the Web.

Use of Open Source Software to Create Learning Objects. In questions ten and eleven, participants were asked about their use of open source software to create learning objects. Although commercially available products like Camtasia and Captivate are commonly used in many libraries, open source or freeware alternatives are often used to create learning objects and especially tutorials. In question 10,43 percent $(n=40)$ of the respondents indicated that they used open source software or freeware to create learning objects. However, 55\% ( $n=51)$ reported that they had not created learning objects yet. Tools that were used are recorded in question 11 (Table 2). A list of the top six tools respondents reported using is provided in the following table.

Sources Used to Find Learning Objects. Question 12 asked participants about the sources they used to find learning objects. The methods used to identify learning objects to deliver instruction, with or without modification, span a wide spectrum. Respondents were able to select more than one response. Listservs were cited as the most frequently used medium to identify learning objects. Figure 7 provides the results to question 12. The heading Tech Trend Reports includes information from Web pages or reports that provide information on innovations in technology and technology needs. Specific mention of sources noted by respondents in the "Other" category

\section{FIGURE 7}

Question 12: What Sources Do You Use To Find Learning Objects (Such As Specific Blogs, Listservs, Feeds, Webpages, Tech Trend Reports? Please List Your Favorite Places. Select All That Apply ( $N=221)$

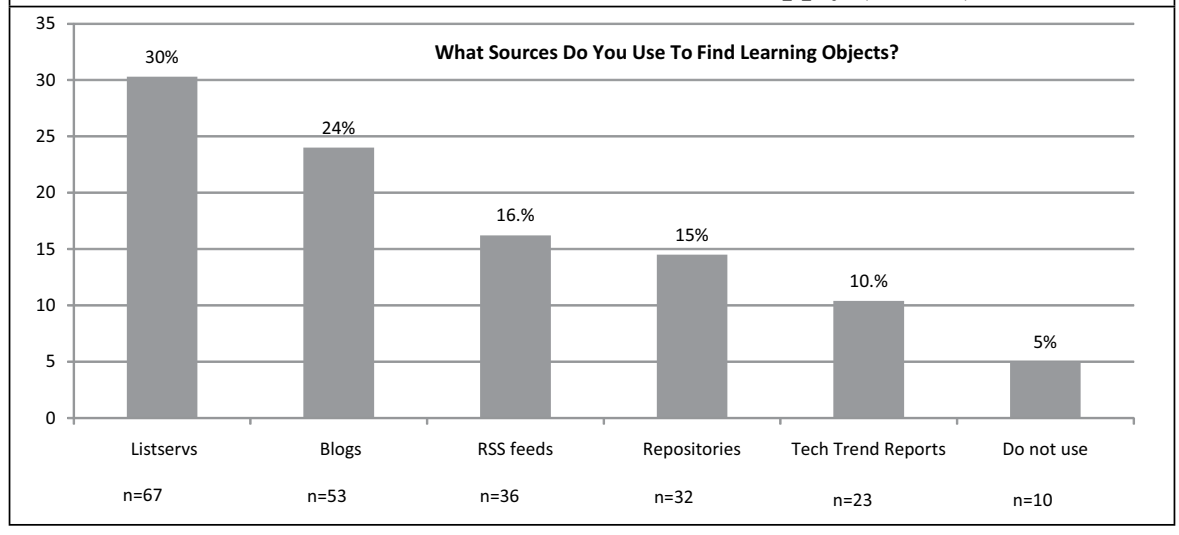




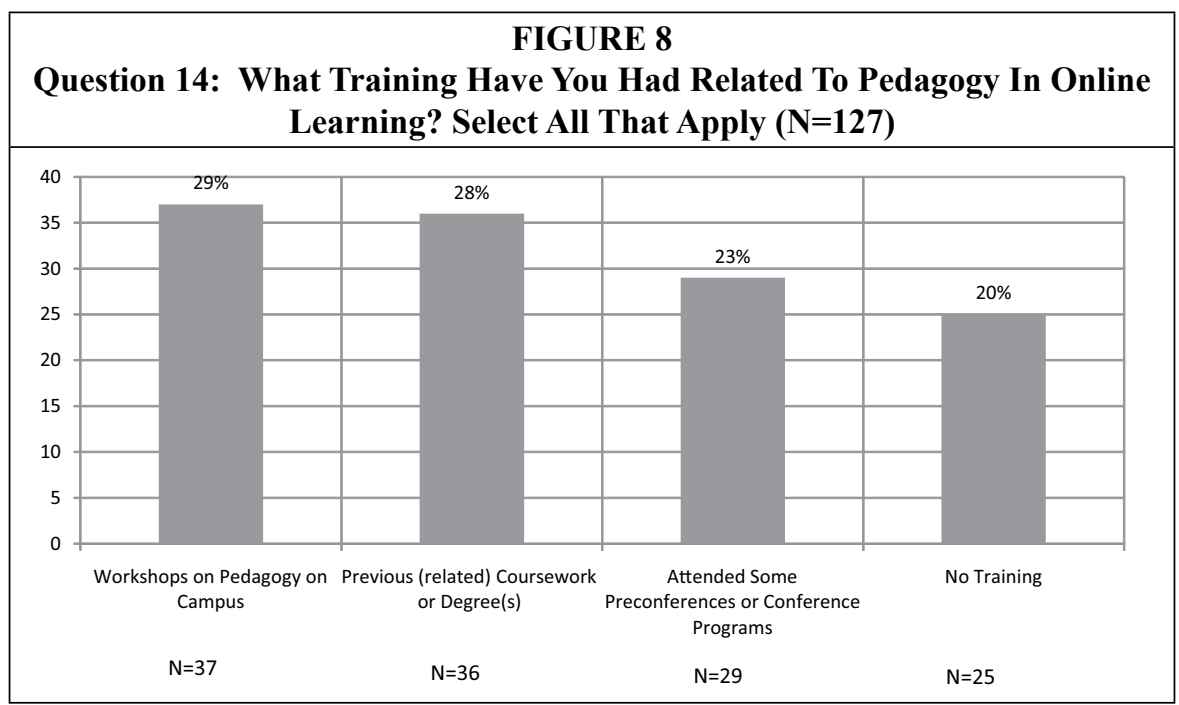

included colleagues, publications, YouTube, and the Web.

\section{Training}

Questions 13 and 14 explored the availability of professional development activities or training for teaching online.

Discussion Group Training. When asked about training for moderating discussions in an online environment (question thirteen, not represented in a figure here), survey participants were encouraged to select all applicable responses. Some respondents had completed teacher training programs, but a majority (63\%) received little formal training about moderating online discussions and - learned on their own. This same response is reflected in the narrative responses to the question, which encompassed reading books, journal articles, and discussion board posts in order to educate themselves on the subject.

Pedagogy in Online Learning Training. Question 14 asked survey participants what training they had completed in preparation for teaching online. As noted in figure 8 above, the responses to this question were rather evenly distributed among the choices. The most common training completed was attendance at campus workshops with a slightly lower number having attended off-campus workshops, preconferences, or conference programs. While over a quarter of the respondents indicated they had completed coursework or programs in the field of education, many had received no formal teacher training. Instead, they relied on one or more workshops or conference programs, with one-fifth (20\%) receiving no formal or informal training.

\section{Evaluating and Designing Learning Objects}

Question 15 asked, "What criteria do you use for evaluating learning objects?" As with some of the previous survey questions, respondents could select more than one response; subsequently, 155 responses were generated for this question. Upon examination of the responses, three major criteria emerged for evaluating learning objects: design, development, and pedagogy.

\section{Design/Development of Learning Objects}

To bring the results into sharper focus, the 36 responses classified under the criterion design/development were further subdivided into the following threads: design principles, ease of use, level of engagement, and instructional technology issues. 
Design Principles. Good design principles reflecting "best practices" were generally perceived as essential, with several respondents indicating a need to create learning objects that are visually appealing and intellectually challenging. Additional considerations deemed important were a clear and logical flow to the delivery of instruction, the inclusion of navigation capabilities that enable participants to pick and choose their path, and the ability to easily step back a level or two within a tutorial. Appropriate assessment activities to measure progress or review exercises integrated throughout the learning object were also noted as being important to ensure instructional effectiveness. Others emphasized the need to incorporate multiple media options (such as audio, video, graphics, or text) to address different learning styles. Although some respondents did not specify how to evaluate learning objects, they nevertheless expressed a need to do so.

Ease of Use. The ability to intuitively navigate within the learning objects was mentioned 11 times as critical. Respondents mentioned that the progression through and manipulation of the object needed to be intuitive.

Level of Engagement. Attributes specifically mentioned by 13 respondents included the need for the learning object to be interesting, fun, and interactive. Interactivity was subsumed under this subcategory based on the belief that, if something is interactive, it may promote engagement and perhaps interject an element of fun. From the responses received, one easy means of including interactivity (and one that is commonly expected) is to incorporate games and challenges into the instructional process.

Instructional Technology Issues. This was identified as a major area of concern at the ALA Midwinter and ACRL discussion groups (mentioned in the Introduction), and 12 survey respondents remarked on the importance of instructional technology to the development and implementation of learning objects. Specific concerns that emerged from the survey included the availability of instructional technology support, sustainability of learning objects, storage needs, functionality, interoperability with various user platforms, customizability, reusability, and accessibility (such as embedding or linking). Two respondents noted the importance of tracking usage statistics and soliciting feedback to inform future iterations and distribution of learning objects.

\section{Pedagogical Considerations}

The second largest category of responses for question 15 (evaluating and designing learning objects) pertained to pedagogical considerations. Comments in this category are subdivided below as: relevance, learning outcomes, learning styles, effectiveness, and best practices.

Relevance. Relevance and the effective use of learning objects engendered many comments. Many of them began with questions, such as: "Does it [the learning object] support the pedagogy I use to teach students? Usually it doesn't. I am struggling to understand how to use existing technology to meet my expectations for the type of instruction that will encourage learning." Similar questions were posed regarding the value or purpose of the learning object, whether or not it was useful to the topic, applicable to the lesson, instructionally effective in achieving desired student learning outcomes, or relevant to students' needs or the course objective. In other words, the respondents felt it was important to critically reflect upon whether or not a learning object would add value to the lesson. Some specific questions were: "What is it trying to show students? ;" "Will it make students think? ;" "Do they meet my students' needs where they are? ;" "Will it make sense to them?;" and "Will it get them where they need to go?"

Learning Outcomes. Not unlike face-toface instruction, respondents recognized that it was essential to address student learning outcomes when developing and evaluating learning objects. Eleven 
respondents also mentioned the need to meet the expectations of both students and librarians when framing the context for providing library skills or research instruction. They recognized that sound learning objectives must be used to frame and create the learning object and that the learning object must be suitable for the learning outcomes of a course, student population, or local environment.

Learning Styles. Several respondents commented that in order for a learning object to be pedagogically effective, it must include multiple instructional options specifically designed to accommodate various learning styles to promote learning for all students, regardless of format.

Effectiveness. Evaluating the effectiveness of learning objects was of concern to at least seven respondents. Comments were provided on the need for a learning object to fulfill a purpose and to assist students to "acquire knowledge which can then be applied in later assignments." Another person added that one must also consider "whether or not the objects help students to learn and research. If they don't help, then they shouldn't be used." One mentioned the importance of considering the "effectiveness of the instructional strategies employed in the learning object." In both the survey responses and during the discussion sessions mentioned above, librarians mentioned the need to know more about whether the time involved in creating objects resulted in increased student comprehension, or whether students learn just as well with a Web page and screenshots?

Best Practices. In general, respondents voiced the need for standards or "best practices" to provide guidelines for designing, developing, and implementing learning objects. Even though there are a number of best practices for design principles, three respondents mentioned that librarians need to look for best practices for pedagogy for online instruction to help them "know if the pedagogy is appropriate."
Question 16: What would you like to know about learning objects and/or creating learning objects?

Some of the themes that emerged from this question were: the need for librarians to know how to create learning objects in a pedagogically sound way, including evidence of what is good pedagogy in the online environment; ways to engage students; and research that provides evidence of the impact of learning objects on student learning. To that end, respondents indicated a desire to pursue professional development opportunities to provide librarians with a sound background in the technology (such as hardware, software, and course/learning management systems) and pedagogy associated with the design, development, and implementation of learning objects in an online environment. Several librarians were at a level where they were ready to make more elaborate learning objects, including incorporating interactivity, games, puzzles, and quizzes, but didn't know where to turn for guidance. Another area of need was to learn more about how to embed learning objects in course/learning management systems.

The need for a checklist of "best practices," examples in demonstrating "best practices," and learning object repositories was noted by many respondents. It was also suggested that "ACRL make a checklist of best practices for designing/evaluating digital learning objects." In the same vein, forty-three librarians mentioned that they wanted to know anything and everything about creating learning objects, especially from their colleagues, particularly what is successful and unsuccessful when creating learning objects. Another desire was to learn "How I can improve my knowledge of creating good learning objects tied to ACRL Standards."

\section{Discussion}

Overall, respondents wanted to learn how to develop pedagogically sound, interactive, and effective learning objects 
designed to promote and document the achievement of student learning outcomes within an online instructional environment. All three hypotheses were supported, and the survey responses provide a glimpse into some of the challenges and issues librarians encounter as they strive to create an online presence for library instruction, whether through the use of individual objects or objects included in course/learning management systems:

Hypothesis 1: Librarians who create online learning objects typically do so without much support or organized training, which may limit the types of objects they can create.

Librarians use a variety of means to acquire the knowledge and skills necessary to create learning objects. However, as discussed in this article, little support or organized training is provided for assisting librarians in the creation of learning objects. Sixty-eight percent of the respondents acquired and learned how to use software applications on their own. Respondents did pursue professional development opportunities, such as attending workshops and training sessions, in addition to reading the literature, but many expressed a real need for more training in how to create learning objects. A possible follow-up question for another larger scale iteration of the survey would be to assess how effective each professional development activity was in improving one's knowledge and skills for designing, developing, and implementing learning objects. Soliciting other possible venues (such as Web sites, blogs, and YouTube videos) for acquiring information about the use of learning objects to deliver instruction would also be valuable.

Hypothesis 2: Librarians who work with faculty and their course management systems tend to have to do so through a faculty course, rather than through a library course where students are automatically enrolled.

Results indicated that the vast majority of librarians (approximately three quarters) had not established their own library course management space. One of the values of having a library designated space within a course management system is that modules created by the library can be accessed by all, rather than only by students enrolled in the course. Additionally, if the library creates a learning module within a course/learning management system, it can be exported to a specific course, thus increasing the visibility and access to library information and instruction components.

A troubling statistic is that only 18 percent of respondents have administrator rights to course sites. Not having administrator rights to a course, or a library-specific course, impedes the ability of librarians to establish a working relationship with faculty members and to gain entrée into their courses. For maximum integration, the library should be a component in each online course. The efforts and challenges to make this a reality can, at times, be monumental. Librarians need to establish and maintain an ongoing dialogue with faculty members, understand course objectives, and become familiar with syllabi and student assignments if they are to create effective learning modules that can be seamlessly embedded into courses. Often, the lack of a presence within course/learning management systems can result in librarians constructing learning modules or Web pages outside the course, thereby relying on faculty to link to the instruction sites. Such efforts run the risk of failing to meet student needs as the course evolves. Increased access to courses permits librarians to quickly add and revise content to match the needs of the students. An encouraging note is the number of librarians who do have instructor access to course management sites, which affords them some privileges.

These results emphasize the need for libraries to work with their campus course/ learning management systems to create a dedicated library space where librarians can create courses and content available to all. If libraries do not have this space, the ability of students to access the library content may be severely limited unless librarians are able to embed the content within faculty courses. 
Hypothesis 3: When designing learning objects, librarians are generally not aware of the best practices or how to design pedagogically sound objects.

A quarter of the survey respondents indicated having little or no training in online learning pedagogy. Those who had training relied mostly on workshops, classes, preconference, or conference programs on the subject. Additionally, training in using discussion groups, in moderating discussions, and in the effective use of instructional technology was minimal. In fact, 63 percent of respondents learned about commonly used Web 2.0 tools on their own. Given the overall lack of support to assist librarians in the development of learning objects, it is not surprising that most are unaware of the pedagogic theories and principles associated with their design. The literature review provided at the beginning of this article emphasizes that effective online instruction requires a familiarity with and implementation of pedagogical concepts, principles, and theories upon which "best practices" in online instruction are based.

\section{Conclusion}

Results from the survey and discussions facilitated by members of the EBSS Online Learning Research Committee highlight the number and variety of technologies librarians are using - technologies that are becoming increasingly integrated into the process for delivering instruction. Learning objects can play a major role in addressing the online instructional needs of students if designed in a pedagogically sound way, and can offer multiple modes for interacting with material. Educators can offer stimulating ways for students to engage socially, cognitively, and intellectually with the information and to gain information literacy skills. Students expect to use the same technology in the classroom as they do in their daily lives. This integration of technology into courses allows students to create their own learning experiences. Teachers, educators, librarians and trainers need to be equipped to meet this demand. The responses from this survey can be used as an indicator of the interest librarians have in creating online instruction and the need for more training venues, both in designing effective learning objects and in identifying the best pedagogically sound practices for teaching in an online environment. The results also highlight a need for a library course/learning management space so that librarians can more proactively participate in online learning.

Although the number of respondents was limited, the intent of this study was not to be exhaustive, but rather to learn which tools are being used by librarians. Goals of the survey included collecting some preliminary data regarding librarians' use of course/learning management systems and identifying the training librarians receive in creating learning objects, as well as their training in moderating online discussions. It is clear from the results that librarians need more support in their efforts for creating pedagogically sound learning objects, which may include closer collaboration with educational technology and teacher training experts on campus. Additionally, librarians would like to have their own course management space so they can more easily embed and disseminate their learning objects within faculty courses. The responses from the discussions and survey informed the development of the Librarian's Toolkit for Online Course Development (see appendix).

Currently within this fast-paced, technologically innovative environment, librarians are presented with many opportunities to capitalize on the benefits to be derived from interactive and collaborative teaching strategies for delivering online instruction. New communication technologies challenge librarians to engage in conversations and exploit teachable moments in a venue where students commonly create and share knowledge. If librarians do not meet this challenge, students may fail in their attempts to become information literate. 


\section{Appendix}

The Librarian's Toolkit for Online Course Development is an online resource developed by the EBSS Online Learning Research Committee during 2007-2010 and can be accessed at: http://wikis.ala.org/acrl/index.php/Online_Learning_Toolkit. It provides examples, tips, and strategies that promote student participation online through the use of several forms of technology and interactive activities. Categories include:

- Pedagogy and Discussion: Included here are tips and strategies for facilitating an online discussion; cooperative and collaborative learning using social software applications; engaging students to be active learners; and how to create good online assignments.

- Learning Materials/Objects: Included in this section are tools available to assist in the creation of video tutorials, podcasts, screen captures, quizzes, polling, games, Web development, and document sharing that librarians can use for the creation of screencasts, presentations, how-to sessions, and interactive demonstrations.

- Web Conferencing Tools: This section includes tools (many open source) that can be used to conduct online meetings, reference interactions, or classes. Included are a variety of tools that offer visual as well as auditory options.

- Course/Content Management Examples: This section provides comparisons and features of several of the course management systems. Also provided are links to tutorials, training, tips, and must-know items for librarians using these systems.

\section{- Bibliography}

\section{Notes}

1. Doug L. Cook and Ryan L. Sittler (Eds.), Practical Pedagogy for Library Instructors: 17 Innovative Strategies to Improve Student Learning (Chicago: American Library Association, 2009).

2. David A. Wiley, "Connecting Learning Objects to Instructional Design Theory:

A Definition, a Metaphor, and a Taxonomy," in The Instructional Use of Learning Objects, ed. D.A. Wiley (2000). Available online at http://reusability.org/read/. [Accessed 1 April 2011].

3. Ibid., 3.

4. Lori Mardis and Connie Jo Ury, "Innovation: An LO Library: Reuse of Learning Objects," Reference Services Review, 36 (2008): 389-413.

5. Robert Keown, "Learning Objects: What Are They and Why Should We Use Them in Distance Education?" Distance Learning 4 (2007): 73-77.

6. John Holmes, "Online Learning Objects: Helping Faculty Teach Information Literacy (And More),"Public Services Quarterly, 1 (2003): 1-9; Warren Longmire, A Primer on Learning Objects (2000). The American Society for Training and Development (ASTD). http://www.astd. org/LC/2000/0300_longmire.htm (Accessed 1 April 2011).

7. Holmes, “Online Learning Objects: Helping Faculty Teach Information Literacy (And More)," 1-9.

8. Cathy Jackson and Rebecca Mogg, "The Information Literacy Resource Bank: Re-Purposing the Wheel," Journal of Information Literacy 1 (2007): 49-53.

9. Keown, "Learning Objects," 73-77; Mardis and Ury, "Innovation: An LO Library: Reuse of Learning Objects," 389-413.

10. Keown, "Learning Objects," 75.

11. Ibid., 77.

12. Mardis and Ury, "Innovation: An LO library: Reuse of Learning Objects," 389-413.

13. Walter O. Dick, Lou Carey, and James O. Carey, The Systematic Design of Instruction, 6th ed. (Boston: Allyn \& Bacon, 2005), 6-8.

14. Grant P. Wiggins and Jay McTighe, Understanding by Design (Upper Saddle River, N.J.: Pearson Education, 2005). 
15. Ibid., 338.

16. Ibid., 84 .

17. Kelvin Thompson and Francisca Yonekura, "Practical Guidelines for Learning Object Granularity from One Higher Education Setting," Interdisciplinary Journal of Knowledge and Learning Objects, 1 (2005): 163-179. http://ijklo.org/Volume1/v1p163-179Thompson.pdf (Accessed 1 April 2011).

18. Marlene Scardamalia and Carl Bereiter, "Knowledge Building," in Encyclopedia of Education, 2nd ed., vol. 4 (New York: Thomson Gale, 2003): 1370-73.

19. Knowledge," In Barry Smith (Ed.) Liberal Education in a Knowledge Society (Chicago: Open Court, 2002): 67-98. http://www.ikit.org/fulltext/inpressCollectiveCog.pdf (Accessed 1 April 2011).

20. David Hung, "Design Principles for Web-Based Learning; Implications for Vygotskian Thought," Educational Technology 41 (2001): 33-41; David Hung and Maish Nichani, "Constructivism and E-learning: Balancing between the Individual and Social Levels of Cognition," Educational Technology 41 (2001): 40-44; Qing Li, "Knowledge Building Community: Keys for Using Online Forums," TechTrends: Linking Research E Practice to Improve Learning, 48 (2004): 24-28, 70; Ken Allen, "Online Learning: Constructivism and Conversation as an Approach to Learning," Innovations in Education and Teaching International, 42 (2005): 247-56; Keith Harman and Alex Koohang, "Discussion Board: A Learning Object," Interdisciplinary Journal of Knowledge E Learning Objects, 1 (2005): 67-77, available online at http://ijello.org/Volume1/v1p067-077Harman.pdf (accessed 21 April 2010); Alex Koohang, Liz Riley, Terry Smith, and Jeanne Schreurs, "E-Learning and Constructivism: From Theory to Application," Interdisciplinary Journal of E-learning and Learning Objects, 5 (2009): 92-109, available online at http://ijklo.org/Volume5/IJELLOv5p091-109Koohang655.pdf (accessed 21 April 2010).

\section{In the Inrricane's Eye: Challenges of Collecting in the 21st Century}

In the last several years special collections and archives have assumed a new and more prominent role within our larger host institutions as well as in the wider library community. Once perceived as peripheral to core library services, our collections are now viewed as central. Despite-or perhaps because of - this centrality, we face a perfect storm of increasing needs in a time of decreasing support. How can we keep building and providing effective access to collections that will remain central in the future, fulfilling our obligation to provide stewardship of the cultural record? Join us at the 52nd Annual RBMS Preconference and find out!

\section{www.rbms.info}

\section{2nd Annual RBMS Preconference Baton Rouge, LA June 21- 24, 2011}

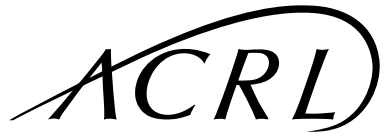

Association of College \& Research Libraries

A Division of the American Library Association

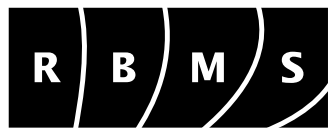

50 East Huron Street | Chicago, IL | www.acrl.org | acrl@ala.org 